Beuzeville - RD675 : secteur 3, site 3

$\mathrm{n}^{\circ} 17-2289$

\title{
Pierre Wech
}

\section{(2) OpenEdition}

\section{Journals}

Édition électronique

URL : http://journals.openedition.org/adlfi/16505

ISSN : 2114-0502

Éditeur

Ministère de la culture

Référence électronique

Pierre Wech, «Beuzeville - RD675 : secteur 3, site 3 », ADLFI. Archéologie de la France - Informations [En ligne], Haute-Normandie, mis en ligne le 17 février 2016, consulté le 01 mai 2019. URL : http:// journals.openedition.org/adlfi/16505

Ce document a été généré automatiquement le 1 mai 2019.

(C) Ministère de la Culture et de la Communication, CNRS 


\section{Beuzeville - RD675 : secteur 3, site 3}

$\mathrm{n}^{\circ} 17-2289$

\section{Pierre Wech}

Code INSEE commune : 27065

Lien Atlas (MCC) :

http://atlas.patrimoines.culture.fr/atlas/trunk/index.php?

ap_theme=DOM_2.01.02\&ap_bbox=0.298;49.309;0.379;49.373

1 Le projet de contournement routier de l'agglomération de Beuzeville a motivé la prescription d'un diagnostic (Wech, 2010), lequel a mis en évidence l'existence, au lieu-dit Campagne de Blacquemare, des vestiges d'un habitat rural gallo-romain.

2 La fouille réalisée suite à ce diagnostic, sur une surface de $5100 \mathrm{~m}^{2}$, a permis de mettre partiellement au jour un système d'enclos fossoyés et de réseaux parcellaires antiques, reflétant la mise en valeur du terroir local dans le cadre d'une probable exploitation agricole gallo-romaine, occupée aux $\mathrm{I}^{\mathrm{er}}$ et $\mathrm{II}^{\mathrm{e}}$ s. apr. J.-C. Aucune occupation ne semble avoir précédé cet établissement.

3 La configuration particulière de l'emprise à fouiller n'a malheureusement pas permis de reconnaître la morphologie de cette exploitation, ni même d'identifier les activités spécifiques qui s'y déroulaient. L'indigence du mobilier mis au jour dans le comblement des structures fouillées ne permet pas davantage de s'interroger sur le statut ou le niveau social des occupants des lieux.

4 Cette occupation semble cesser dans le courant $d u \mathrm{II}^{\mathrm{e}} \mathrm{s}$. Les terrains n'ont, par la suite, connu aucune occupation autre que purement agricole (traces de parcellaire moderne et contemporain).

5 Cette fouille, avec celle réalisée au lieu-dit la Pomme d'Or (Wech, 2010) contribue néanmoins à notre connaissance de l'occupation antique du Lieuvin, et plus généralement du pays d'Auge.

6 Cette région normande, considérée jusqu'ici comme un désert archéologique, faute d'investigation, livre aujourd'hui, au gré des fouilles récentes, les éléments d'un maillage 
assez serré d'établissements ruraux d'envergure variable. Le Lieuvin semble ainsi avoir été un terroir largement exploité et mis en valeur durant l'Antiquité.

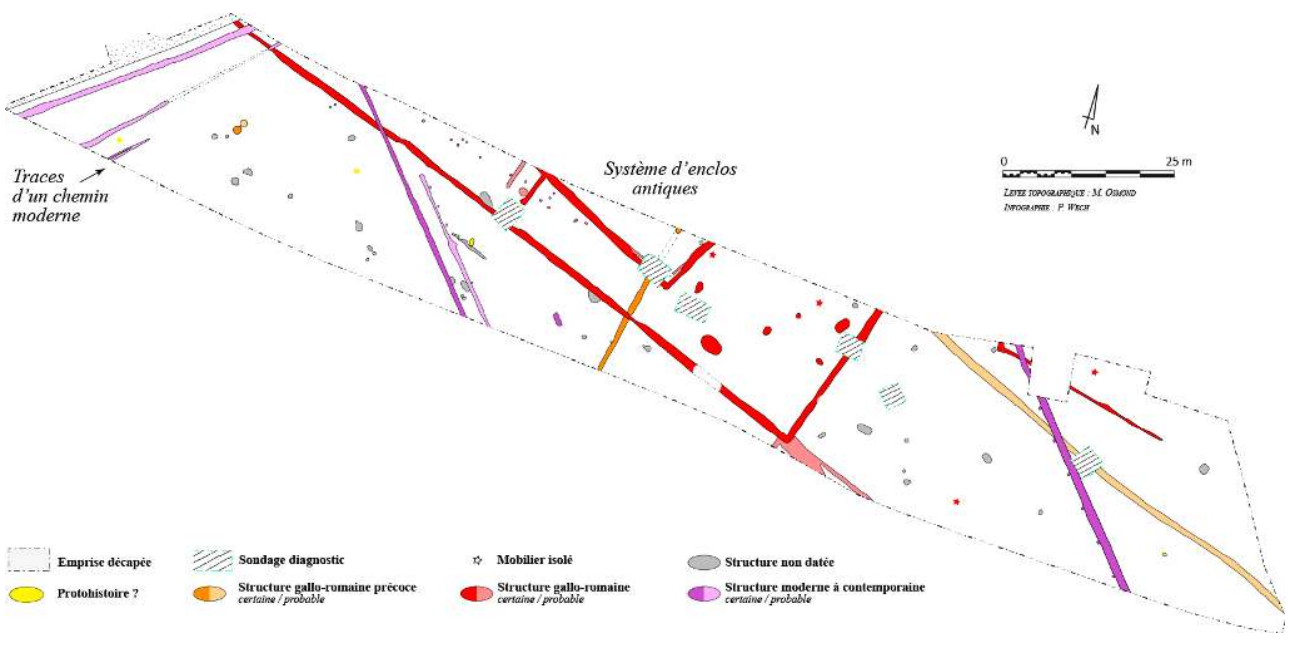

Fig. 1

Plan phasé

P. Wech

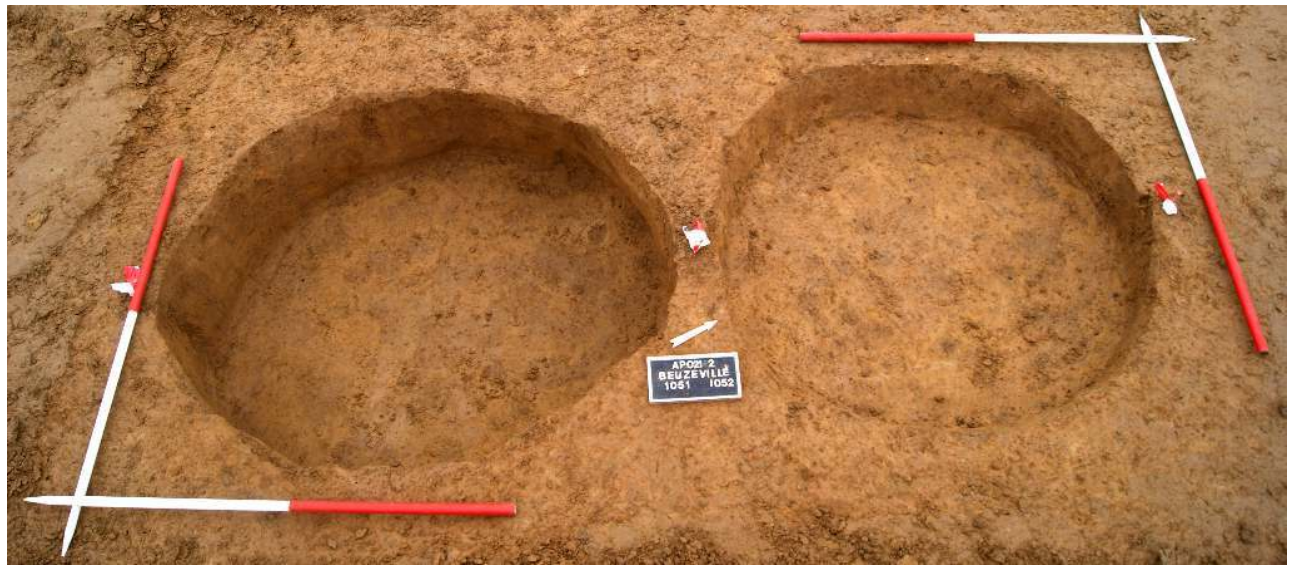

Fig. 2

Groupe de deux possibles silos

P. Wech

INDEX

Index chronologique : Antiquité

Index géographique : Normandie, Eure (27), Beuzeville

Mots-clés : enclos, fossé, parcellaire

operation Fouille préventive (FP) 